\title{
INTEGRATING INVENTORY AND TRANSPORT CAPACITY PLANNING IN A FOOD SUPPLY CHAIN
}

\author{
Freile, A. J. ; Mula, J. ${ }^{* *} \&$ Campuzano-Bolarin, F. ${ }^{* * *}$ \\ *Universitat Politècnica de València, Research Centre on Production Management and Engineering \\ (CIGIP), Camí de Vera s/n, 46022 Valencia, Spain \\ ** Universitat Politècnica de València, Research Centre on Production Management and Engineering \\ (CIGIP), Plaza Ferrándiz y Carbonell, 2, 03801, Alcoy, Alicante, Spain \\ *** Universidad Politécnica de Cartagena, Department of Business Economics, Spain \\ E-Mail: alvarojosefreile@gmail.com,fmula@cigip.upv.es, francisco.campuzano@upct.es
}

\begin{abstract}
The general objective of this paper is to simulate a supply chain to assess the effects that different inventory management policies and transport capacity systems have on costs (transport) and service levels (stockouts). This paper specifically aimed to facilitate the decision-making process about planning distribution capacities, particularly when contracting a transport fleet in a supply chain under uncertainty with a 1-year time horizon by evaluating different types of scenarios, which vary depending on availability of vehicles and obtaining vehicles. The system dynamics simulation model was applied to a real-world food supply chain and can be adopted by chains related to diversified cropping systems. The results provide the best decision alternative in terms of costs and inventory levels by considering the transport capacity life cycle, the time to acquire additional transport capacity, the reorder point in days of stock and the target inventory.

(Received in June 2020, accepted in August 2020. This paper was with the authors 1 week for 1 revision.)
\end{abstract}

Key Words: Supply Chain, Inventory Management, Transport Capacity Management, Food Sector, Simulation, System Dynamics

\section{INTRODUCTION}

In order to study the performance of inventory management and transport capacity policies in a supply chain, which is more complex in diversified systems, system dynamics was used as an acknowledged form to face problems related with continuous processes [1], where the feedback of the system's variables significantly affect the way the system performs by generating dynamic changes in its performance [2-9]. Here, we adopted the model of Georgiadis et al. [10] as the reference and basis of this work to study and simulate transport management, and also the generic inventory management system designed by Sterman [11], which is also contemplated by [10]. The system of [10] aims to not only facilitate the decision-making process about planning transport capacities in a multi-step supply chain under uncertainty $[12,13]$, but to offer a reference methodology framework that allows a wide range of strategic problems related with supply chain management to be dealt with. In this paper, the model of [10] is extended to include information on input parameters and also on the considered variables. Moreover, several of the original assumptions on which the model is based have been modified to better represent the supply chain's reality, which commercialises foods. Indeed, the sought results differ because the approach given to provide the solution has peculiarities in each case $[14,15]$. Furthermore, the authorship of the scenarios employed throughout this document, and the evaluation of each one, corresponds to the present authors and cannot be found in the reviewed literature. Most of them chiefly focus on inventory management to lower its levels or to reduce the number of unsupplied orders due to stockouts $[16,17]$ and sporadically centre on transport management $[18,19,20]$. In this sense, the necessity of integrating supply chain transport and production planning has been proven in the literature [21, 22]. Therefore, the main contributions of this research are: (i) to extend the applications of system dynamics in the field 
of inventory and transport management; (ii) to simulate a real-world food supply chain; and (iii) to study in an integrated way the effects related to different inventory policies and transport capacities.

This article is arranged as follows: Section 2 presents a literature review of the problem under study. Section 3 both describes the problems to be dealt with, a supply chain and a process to supply finished products. Section 4 proposes the simulation model. Section 5 evaluates the results through the different proposed scenarios. Finally, Section 6 provides conclusions and further research.

\section{LITERATURE REVIEW}

Several types of problems can be solved in transport management, which can involve: analysing infrastructures, the influence of fluctuations in demand in transport management, the relation between transport policies and how inventories perform, etc. [23] managed to synthesise the most relevant research works about modelling system dynamics applied to transport, where the most relevant works focus on transport management, and where infrastructures, new technologies and intermodality as such are not considered in the proposed approach. It is worth highlighting the work of [24], which studies the dynamic performance between the transport infrastructure and a supply chain in the food sector, and which confirms that a correct infrastructure allows a suitable customer service level. Mason and Chandra [25] state that the faster the flow of materials, information and money in a supply chain, the better the customer service and decision making. Transport, on the other hand, is one of the main links that allows the flow of materials, and thus helps the company meet its objective, mostly in diversified systems where transport must be optimized to reduce costs when supplying different commodities. It is worth considering that transport management performance in a supply chain is affected by growing variation in demand in both costs and efficiency [26]. Therefore, most people in charge of managing transport in a company accept that varying demand simply happens, and attempt to adjust its operations in their settings [27]. Accordingly, organisations must make important decisions about fixed transport capacity and owing to peaks in demand, also about what the subcontracted capacity would be. Likewise, in order to meet market demand, organisations must establish safety stock levels. Mula et al. [22] use the system dynamics-based simulation model to better know the balance between transport capacity and inventory levels by considering that these two aspects are inversely proportional. Georgiadis et al. [10] also stress that if input variables, such as demand, are stationary, both system dynamics and discrete event simulation could be used. However, if any variable or parameter, e.g., demand, parameters of inventory policies, etc., is related with time, system dynamics is the most suitable way to study it. In line with this, Angerhofer and Angelides [28] show that most system dynamics address inventory decisions, management policies, extending demand, design and integrating the supply chain.

Regarding inventory management, Guerrin [29] attempts to answer two of the most important questions that arise when organising supplies: when and how much to supply. Through system dynamics, several different inventory scenarios are simulated to analyse how inventory indicators perform. The way that supply orders are placed among supply chain members (e.g., by a reorder point, the economic order quantity, etc.), along with effects of transport restrictions, can affect service levels and inventories [30]. Che [31] uses system dynamics to demonstrate that implementing a supply chain's collaborative management model, e.g., VMI, can significantly improve the economic performance of both the inventory and transport. Total inventory costs can lower the more frequent the journeys made to transport supplies become, and with smaller lot sizes [32]. These last authors also state collaboration can 
enhance transport flexibility, while also improving customer satisfaction and guaranteeing lower total logistics costs.

Transport capacity limitations negatively affect inventories and other supply chain expenses. By simulating the well-known beer game [11] and system dynamics, Spiegler and Naim [33] demonstrate how transport capacity management influences the inventory and other supply chain costs. Decisions made about transport capacity management can even distort demand owing to the lot-sizing strategies adopted to optimise transport capacity and, therefore, how they affect inventory efficiency [34]. System dynamics models applied to analyse how variations in the production and distribution of materials performs by establishing inventory policies, like safety stock, to improve decision making is one of the proposals put forward [35]. Here, the intention is to determine the best way to compensate the results in relation to inventory indicators versus transport and production indicators.

We conclude that many, but not enough, studies have been conducted on how inventory policies perform and on transport capacity management combined by system dynamics. Although we can find separate research works on problem solving that centre on improving the performance of transport resources and on inventory management, fewer works have analysed and assessed the existing relations between both these factors in the identified literature. Several authors stress that the existing relationships between performance indicators in transport management and inventory management are inversely proportional, which leads to a discrepancy while making decisions as to which factor more importance should be attached to, and they focus on making more efforts to improve it. Finally, despite plenty of academic works in the scientific literature intending to solve problems about striking a balance between the performance of inventories and transport in a supply network, system dynamics is found more often because it has been applied more.

\section{PROBLEM DESCRIPTION}

This paper models a conventional supply chain in the frozen foods sector. The supply chain is made up of a factory, located next to the central warehouse $(G) . G$ is in charge of supplying the finished product to two other smaller warehouses located in other cities (M and $\mathrm{P}$ ) by lorries with a transport capacity of 6,500 litres. Another warehouse also exists (Q) which is directly supplied by the factory. Six product families are considered. Regarding secondary distribution, all the above warehouses cover the demand in their areas. This demand is known as presales and is characterised by small points of sale dotted all over the area that they cover.

The product is delivered on refrigerated lorries, whose approximate capacity is 1,200 litres. Attempts are made to put to best use the transport capacity of these lorries when supplying and transferring. Lead times are strictly the set ones because of the standard supply processes followed, and the time to distribute the product to end customers is determined by supply policies. Despite all the warehouses forming part of the same company, each warehouse negotiates with the transport company the lorries' capacity that it requires to distribute to the presales network. As each warehouse has a leader, capacity decisions are made separately by taking into account each warehouse's requirements. Nowadays, these lorries are rented out with contracts, and the contracted quantity has a 20-day duration, e.g., having specified capacity, the number of lorries cannot be reduced until 20 days have elapsed. If one lorry is to be added to the stipulated transport fleet, the company requires notification 5 days beforehand to make that lorry available. However, if one transport unit is required urgently for 1 day, this can be requested, but we must bear in mind that the daily lease of an additional lorry is relatively higher than that paid monthly. Moreover, 6,500-litre lorries and containers are requested 1 or 2 days beforehand to load the product. These lorries are used and paid for per journey, i.e., they are not leased for a given time, but each journey has a specific cost. 


\section{SIMULATION MODEL}

According to the structure contemplated by [10] for transport management and the generic inventory management system of [11], an adaptation was made by bearing in mind the specific characteristics of the supply chain under study; e.g., restricted storage capacities or the process to supply $\mathrm{M}$ and $\mathrm{P}$ by using another means of transport. The objective of the simulation model is to analyse the performance of the described supply chain with different scenarios where certain parameters vary: the time it takes to make available and to obtain lorries, the reorder point and the desired inventory state. Both the analysis of how capacity performs and transport costs form part of this work's specific objectives. Another specific objective is considered: modelling the performance of stock levels and their effects on the service level as regards meeting the demand in the various sales areas by making variations in reorder points and the desired inventory state or the coverage days for each distribution centre.

The flow chart (https://cigip.webs.upv.es/docs/Flowchart.pdf) comprises four distribution networks G, Q, P and M. Distribution network Q is directly supplied by the factory through the orders placed by this warehouse's coordinator, and are transported in a container with a capacity of 15,000 litres. This distribution centre only delivers in its dispatching area and it has its own transport capacity, which is also managed individually. Supply network G is also directly supplied by the factory, but no means of transport is necessary as their premises are adjacent. The factory's supply capacity is not restricted as it has an unlimited product inventory. This distribution network manages its transport capacity individually to cover all the product orders in its sales area. It is worth stressing that this distribution centre supplies the finished product to the warehouses located in sales areas $\mathrm{M}$ and $\mathrm{P}$ when the coordinators of each regional area place a supply order. The distribution centre located in sales area $\mathrm{P}$ is supplied by the finished product from G. It is worth pointing out that in this case, transport capacity is managed independently of the other logistic centres. One of the factors that distinguishes one distribution centre from another is the demand that they meet because if we place them in growing order, demands follow this order: M, P, Q and G. The sales area M is supplied directly from G. The demand covered by this distribution centre is the smallest of the whole supply network and is thus expected to use the fewest resources. As in the other distribution centres, this logistics centre independently manages its transport capacity.

Given $i$ is the set of families of products, Table I defines the level, flow and auxiliary variables of the simulation model.

Table I: Nomenclature.

\begin{tabular}{|c|c|}
\hline \multicolumn{2}{|c|}{ LEVEL VARIABLES } \\
\hline CT & quantity of lorries available to distribute the finished product \\
\hline$F_{i}$ & unlimited finished product $i$ that supplies the distribution centres \\
\hline $\operatorname{In} v_{i}$ & tory level of finished product $i$ in each distribution centre \\
\hline$L S_{i}$ & nding to be delivered to the distribution warehouses \\
\hline \multicolumn{2}{|c|}{ FLOW VARIABLES } \\
\hline Abst $_{i}$ & $\begin{array}{l}\text { Supply: finished product } i \text { is required by the distribution centres that are not directly supplied by } \\
\text { the plant }\end{array}$ \\
\hline$C P_{i}$ & $\begin{array}{l}\text { Supplying orders: the rate at which finished products } i \text { enter the inventory of each distribution } \\
\text { centre, which has a set lead time }\end{array}$ \\
\hline $\boldsymbol{P}_{i}$ & $\begin{array}{l}\text { Orders: order for product } i \text { placed with the factory using the expected demand, the reorder point, } \\
\text { inventory state and the inventory state adjustment }\end{array}$ \\
\hline TACT & $\begin{array}{l}\text { Rate at which transport capacity is obtained: value generated from the extra quantity of required } \\
\text { transport, which takes some time before being obtained }\end{array}$ \\
\hline$T D C T$ & $\begin{array}{l}\text { Transport capacity availability rate: number of lorries that no longer form part of the transport } \\
\text { capacity given some surplus. This rate is influenced by the transport capacity life cycle }\end{array}$ \\
\hline$V_{i}$ & Sales: meeting the demand of $i$ that is restricted by the finished product's inventory level \\
\hline
\end{tabular}




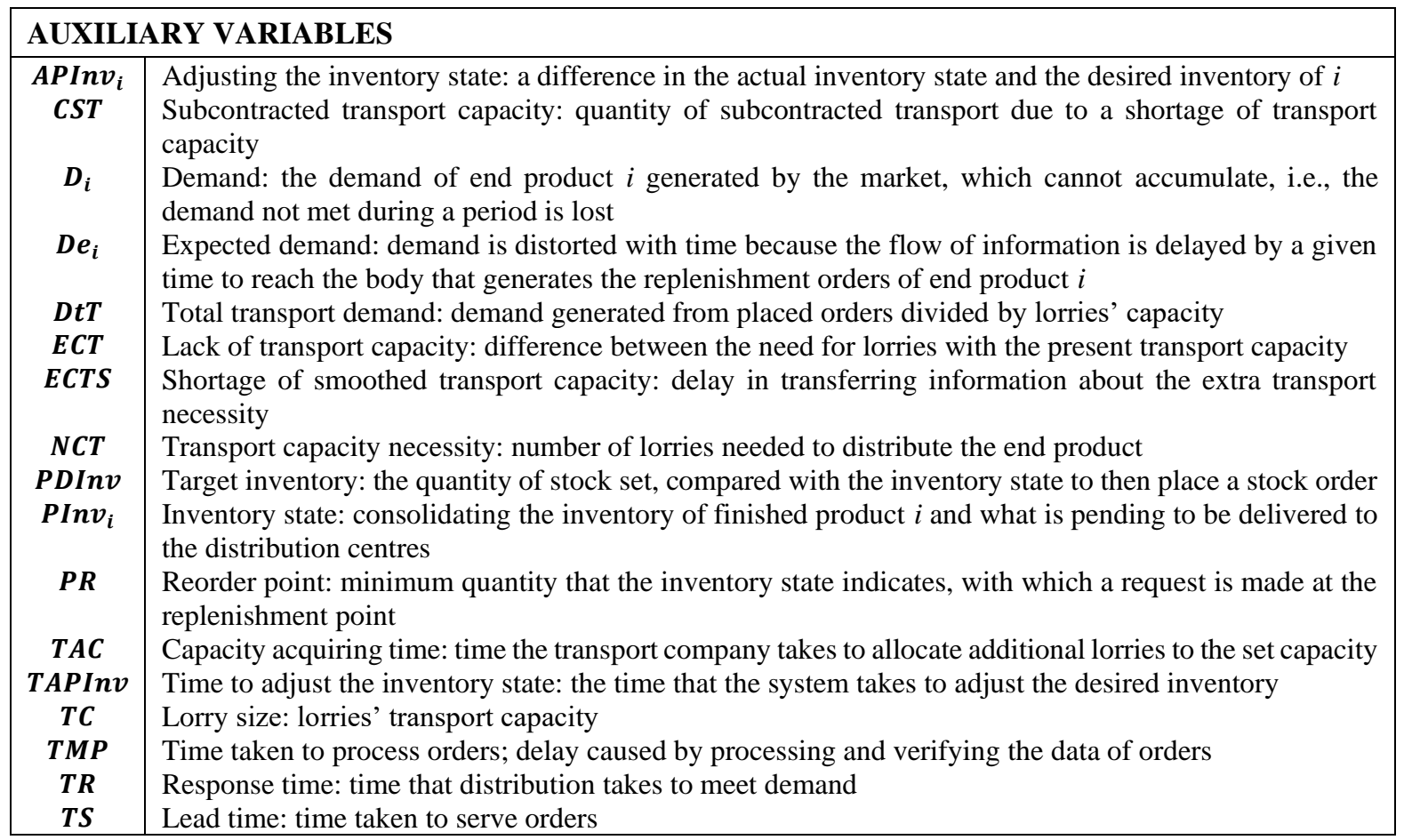

An industrial-strength simulation software has been used for computer simulation, Vensim ${ }^{\circledR}$, which is a simulation interface for system dynamics. The equations of the most relevant variables produced with the $\operatorname{Vensim}^{\circledR}$ simulation software are now generically described. End product demand is presented with a normal random distribution, with its minimum, maximum, average, standard deviation values, plus a seed value. The last value varied every 365 days as it would serve to assess the model for the different random numbers.

$$
D_{i}(t)=\operatorname{INT}[R A N D O M N O R M A L(\min , \max , \text { mean, stdev, seed })]
$$

Expected demand, which is employed by the variable orders to request the product at the plant, is given by:

$$
D e_{i}(t)=D_{i}(t-a)
$$

Sales are given by the minimum value between the inventory found in the warehouse, divided by the response time it may give, or by the demand value.

$$
V_{i}(t)=\min \left(\frac{\operatorname{In} v_{i}(t)}{T R}, D_{i}(t)\right)
$$

Supply is the quantity of finished product requested by the distribution centres that do not receive it directly from the plant ( $\mathrm{M}$ and $\mathrm{P})$.

$$
\operatorname{Abst}_{i}(t)=\sum P_{i}(t)
$$

The inventory level is obtained as the difference between the output elements, given by serving orders, and outputs are given by the sales made during a given period.

$$
\operatorname{Inv} v_{i}(t)=C P_{i}(t)-V_{i}(t)
$$

Serving orders is determined as the input rate of the finished products that go to the inventory of each distribution centre, which also has a set lead time.

$$
C P_{i}(t)=P_{i}(t-T S)
$$

The supply line is determined as the difference between the quantity of product pending to be delivered from the orders and the quantity delivered to the inventory. 


$$
L S_{i}(t)=P_{i}(t)-C P_{i}(t)
$$

The orders are the requested quantity of product that the factory receives from the expected demand and the quantity to be adjusted of the inventory state. To this end, it is necessary to consider the reorder point of each distribution centre, the inventory state and the desired inventory quantity.

$$
P_{i}(t)=\left\{\begin{array}{cl}
D e_{i}+A P \operatorname{Inv} v_{i}, & \text { If } \operatorname{Pinv}_{i}(t)<P R \\
0, & \text { otherwise }
\end{array}\right.
$$

The inventory state is the establishment of the finished product inventory and what is pending to be delivered to the distribution centres.

$$
P \operatorname{Inv} v_{i}(t)=\operatorname{Inv}_{i}(t)+L S_{i}(t)
$$

To determine the inventory state adjustment value, the maximum quantity between the difference between the desired inventory state and the inventory state of each distribution centre and zero is selected, and is then divided by the time to adjust the inventory state.

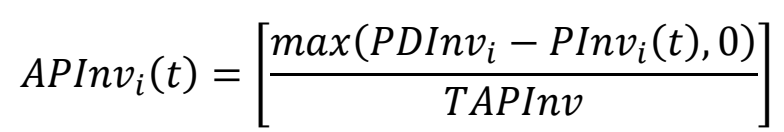

The total transport demand is the demand generated with placed orders, divided by lorries' capacity.

$$
\operatorname{DtT}(t)=\frac{\sum_{i=1}^{6} P_{i}(t)}{T C}
$$

Lack of transport capacity is obtained with the maximum quantity between the difference between the transport capacity requirement and the installed capacity, and the zero value.

$$
\operatorname{ECT}(t)=\max [N C T(t)-C T(t)]
$$

The rate of obtaining transport capacity is the value generated with the extra quantity of required transport, which takes some time before it is obtained.

$$
\operatorname{TACT}(t)=\operatorname{ECTS}(t-T A)
$$

Transport capacity is the quantity of available lorries to distribute the finished product calculated with the difference between obtaining the transport rate and the available transport capacity rate.

$$
C T(t)=\operatorname{INT}(T A C T(t)-T D C T(t))
$$

The available transport capacity rate is the quantity of lorries that no longer form part of the transport capacity due to a surplus. This rate is influenced by the transport capacity life cycle.

$$
\operatorname{TDCT}(t)=\frac{C T(t)}{C V C}
$$

\section{EVALUATION OF RESULTS}

Table II presents the current data and the different scenarios to be simulated.

Table II: Scenarios (Scen.) for planning distribution capacities and inventory management.

\begin{tabular}{|l|c|c|c|c|c|c|c|c|}
\cline { 2 - 9 } \multicolumn{1}{c|}{} & $\begin{array}{c}\text { Current } \\
\text { situation }\end{array}$ & $\begin{array}{c}\text { Scen. } \\
\mathbf{1}\end{array}$ & $\begin{array}{c}\text { Scen. } \\
\mathbf{2}\end{array}$ & $\begin{array}{c}\text { Scen. } \\
\mathbf{3}\end{array}$ & $\begin{array}{c}\text { Scen. } \\
\mathbf{4}\end{array}$ & $\begin{array}{c}\text { Scen. } \\
\mathbf{5}\end{array}$ & $\begin{array}{c}\text { Scen. } \\
\mathbf{6}\end{array}$ & $\begin{array}{c}\text { Scen. } \\
\mathbf{7}\end{array}$ \\
\hline Availability time (days) & 20 & 30 & 20 & 10 & 5 & 30 & 30 & 30 \\
\hline Time to be obtained (days) & 5 & 7 & 5 & 3 & 1 & 7 & 7 & 7 \\
\hline Reorder point (days) & 5 & 7 & 7 & 7 & 7 & 5 & 3 & 1 \\
\hline Desired inventory state (days) & 10 & 7 & 7 & 7 & 7 & 10 & 13 & 16 \\
\hline
\end{tabular}


Twenty iterations were done with different random numbers. To start with, the model that represented the current state was simulated, for which the following results were obtained for stockout and transport costs (Table III). It is noteworthy that the data of the product families were established and calculations were done in an aggregate manner. With the results obtained by evaluating simulation, the intention was to also identify the correlation between the variation in the parameters and the results obtained in terms of customer service (stockouts) and the costs of logistics (transport costs).

Table III: Simulation results.

\begin{tabular}{|c|c|c|c|c|c|c|c|c|}
\cline { 2 - 8 } \multicolumn{1}{c|}{} & $\begin{array}{c}\text { Current } \\
\text { situation }\end{array}$ & Scen. 1 & Scen. 2 & Scen. 3 & Scen. 4 & Scen. 5 & Scen. 6 & Scen. 7 \\
\hline $\begin{array}{c}\text { Stockout } \\
\text { G }\end{array}$ & 741,285 & 329,041 & 329,041 & 329,041 & 329,041 & 741,285 & 989,635 & 913,853 \\
\hline $\begin{array}{c}\text { Stockout } \\
\text { Q }\end{array}$ & 32,519 & 0 & 0 & 0 & 0 & 32,519 & 107,819 & 145,148 \\
\hline $\begin{array}{c}\text { Stockout } \\
\text { P }\end{array}$ & 742 & 0 & 0 & 0 & 0 & 742 & 54,402 & 96,432 \\
\hline $\begin{array}{c}\text { Stockout } \\
\text { M }\end{array}$ & 903 & 0 & 0 & 0 & 0 & 903 & 48,271 & 78,235 \\
\hline $\begin{array}{c}\text { Total } \\
\text { Stockout }\end{array}$ & 775,448 & 329,041 & 329,041 & 329,041 & 329,041 & 775,488 & $1,200,126$ & $1,233,667$ \\
\hline $\begin{array}{c}\text { Transport } \\
\text { costs G }\end{array}$ & $\$ 1,886,441.2$ & $\$ 1,811,376.2$ & $\$ 1,812,060.4$ & $\$ 1,865,795.9$ & $\$ 1,943,523.1$ & $\$ 1,844,220.5$ & $\$ 1,884,613$ & $\$ 1,900,030.1$ \\
\hline $\begin{array}{c}\text { Transport } \\
\text { costs Q }\end{array}$ & $\$ 1,846,187.1$ & $\$ 1,837,655.8$ & $\$ 1,837,655.8$ & $\$ 1,839,312.3$ & $\$ 1,900,038.1$ & $\$ 1,838,240.5$ & $\$ 1,853,007.8$ & $\$ 1,895,480.2$ \\
\hline $\begin{array}{c}\text { Transport } \\
\text { costs P }\end{array}$ & $\$ 978,195.4$ & $\$ 978,124.8$ & $\$ 978,054.2$ & $\$ 978,054.2$ & $\$ 978,324.9$ & $\$ 978,195.4$ & $\$ 978,383.7$ & $\$ 978,560.3$ \\
\hline $\begin{array}{c}\text { Transport } \\
\text { costs M }\end{array}$ & $\$ 559,098.4$ & $\$ 559,038.7$ & $\$ 559,002.8$ & $\$ 559,002.8$ & $\$ 558,990.9$ & $\$ 559,098.4$ & $\$ 559,217.9$ & $\$ 559,337.4$ \\
\hline $\begin{array}{c}\text { Total } \\
\text { transport } \\
\text { costs }\end{array}$ & $\$ 5,269,922.1$ & $\$ 5,186,195.5$ & $\$ 5,186,773.2$ & $\$ 5,242,165.2$ & $\$ 5,380,877$ & $\$ 5,219,754.8$ & $\$ 5,275,222.4$ & $\$ 5,333,408$ \\
\hline
\end{tabular}

The way to calculate the stockout for all the distribution centres is based on the difference in demand and the sales made in each one. To calculate transport costs, it is necessary to bear in mind the cost of hiring the fleet and the number of hired lorries, as well as the lorries subcontracted per day to cover all the presales supplies. After simulating the previously established scenarios and the different iterations, the average results of transport costs and stockouts were used for all the distribution centres. To then compare scenarios, only the summation of these analysed factors was considered. The best result for the quantity of product with a stockout is obtained by configuring the reorder point and the desired inventory state with a 7-day stock because, as shown, transport management does not affect inventory management. The lowest cost is given by Scenario 1, where the transport capacity life cycle is 30 days and the time to obtain transport is 7 days as it shows the lowest costs for monthly rentals and for daily further capacity subcontracts. Having obtained these results, the best option for the simulated parameters are presented in Scenario 1 as it provides a small quantity of the product with a stockout and lower costs for managing transport capacity planning. Despite the results for the percentage of the total transport cost obtained in Scenario 1 being similar to that presented in Scenario 2, it is worth having longer times to obtain and have transport capacity available because this confers the transport company's fleet of lorries more stability. This is because fluctuation could take place in the supplier's transport management when shifting from 30 days to 20 days, which could increase its set costs for fleet availability by perhaps leading to an increase in these costs in future negotiations. Fig. 1 shows the variation in the inventory in distribution centre G, M, P and Q when the parameters from Scenario 1 were used. In centre $\mathrm{Q}$, we could identify that the inventory of all the product families often reaches zero. This is because this distribution centre must not only meet the requirements of its adjacent market, but 
must also supply distribution centres $\mathrm{M}$ and $\mathrm{P}$. We could also see that the inventories in $\mathrm{M}, \mathrm{P}$ and Q can barely reach a value of zero, which could be due to the inventory policies that these warehouses employ being ideal for the surroundings they find themselves in. However, for warehouse Q, it is worth stressing that although its inventory never reaches zero, this warehouse has very marked peaks, which almost reach logistic centre G's levels.

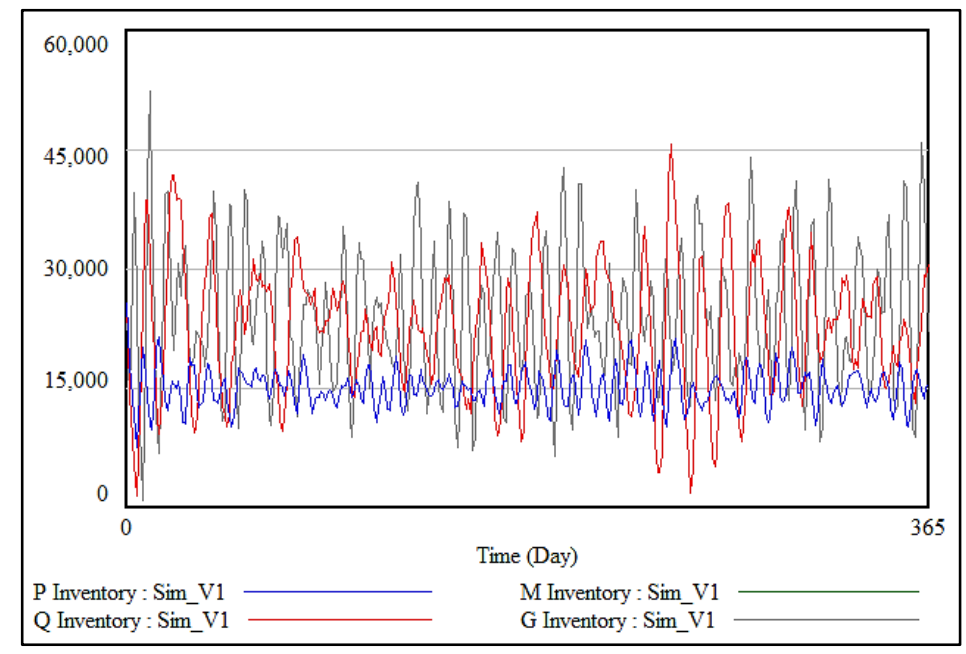

Figure 1: Total inventory.

Fig. 2 shows how the variable transport capacity performs for the four distribution centres, which is created with the data of Scenario 1 on a 365-day horizon. As we can see, as all these distribution centres start with zero transport capacity, the system is considerably disturbed when the process begins, which sharply increases transport capacity. After approximately 30 days (this being the transport capacity life cycle), it starts to descend when the real required transport capacity is adjusted. We can also see that the transport capacity in distribution centre $\mathrm{M}$ is the lowest because less product is demanded, followed by warehouse G. This is followed by logistic centres $\mathrm{P}$ and $\mathrm{Q}$, which maintain the same transport fleet after a period.

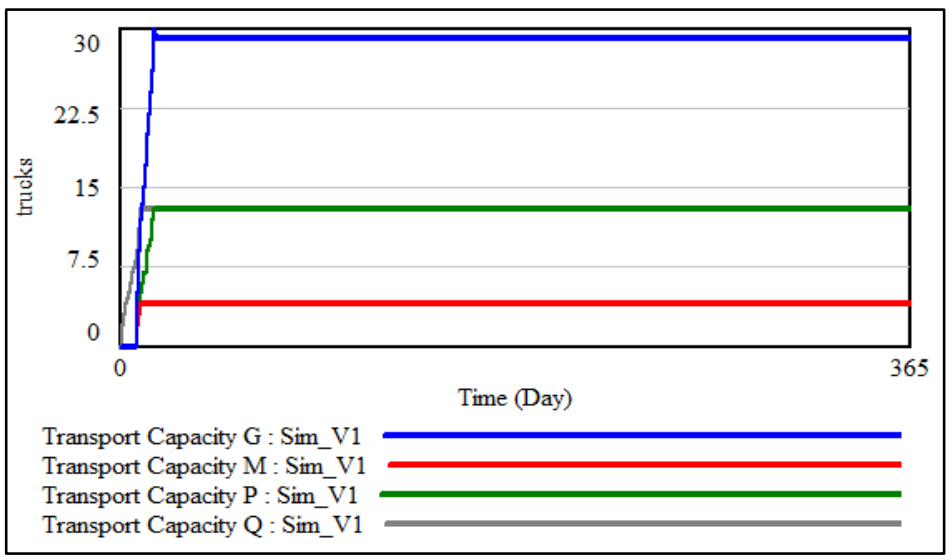

Figure 2: Transport capacity.

Accordingly, we find that the inventory policies should be separately revised, with special emphasis placed on the reorder point and the desired inventory state; i.e., each distribution centre should calculate and establish the desired stock levels and the quantity required to meet its demand.

Additionally, after employing the Causes Strips tool of the Vensim ${ }^{\circledR}$, the sources of oscillation in the sales variable can be seen in distribution centre $G$ and for product family. Fig. 3 presents the results for product family PAL. As we can see, the ascending and descending 
inventory peaks are present in PAL. This is because their products have a high mean demand and fluctuation. We can also see that the inventory often reaches zero. This is because this distribution centre $\mathrm{G}$ must not only meet the requirements of its adjacent market, but must also supply distribution centres $\mathrm{M}$ and $\mathrm{P}$. In the other graphs, similar performance is noted for the relationship among variables.

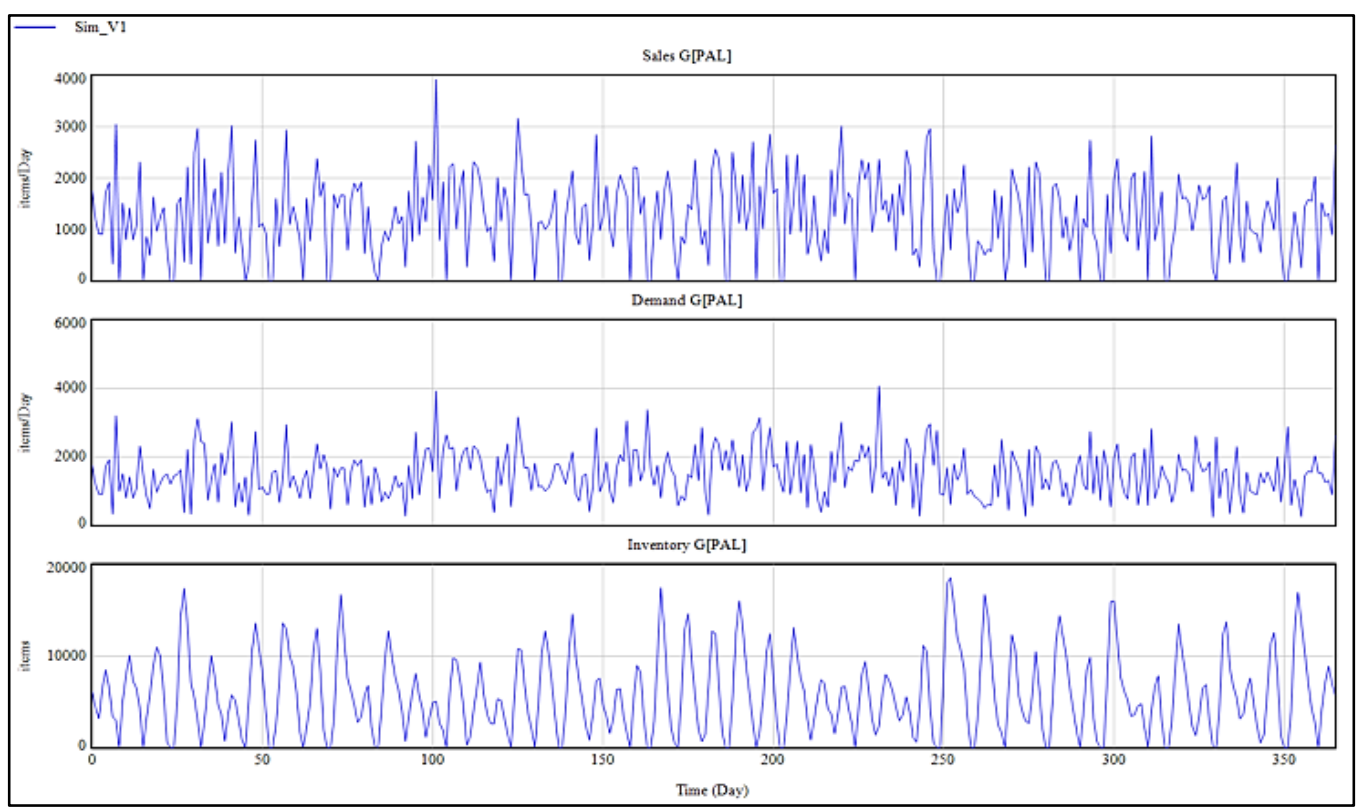

Figure 3: Relationship among the demand, added orders and inventory in sales variables.

The results obtained for the model simulated in Vensim ${ }^{\circledR}$ are robust because, as the parameters change according to the same tendency, the results also change, and no abrupt results are obtained when a change is made in the input data. Despite what has been previously described, a process is followed to alter the values of some model parameters by employing the Monte Carlo simulation in the Vensim ${ }^{\circledR}$ programme, which is also known as multivariate sensitivity simulation. For the present model, 300 further simulations to the predefined one were run, and the following parameters automatically changed: capacity life cycle, desired inventory state, reorder point and availability time. In all these simulations, the standard simulation for all the variables that take the values of the initial model parameters was maintained so we could also view this alternative. These parameters were selected to be analysed because they vary in the simulation of the various scenarios, and also because lorries' capacities, the times taken to process orders, and other constants are data that are unlikely to be modified. For all these constants, minimum and maximum values are established when this analysis is carried out. These values are as follows: from 5 to 30 for the capacity life cycle, from 7 to 16 for the desired inventory state, from 1 to 7 for the reorder point and, finally, from 1 to 7 for the time to be obtained. These minimum and maximum values are defined with the ranges of scenarios before being considered. It is also noteworthy that the uniform random likelihood distribution was established to carry out the sensitivity analysis. Next the variables to be analysed were defined: transport capacity $\mathrm{G}$, the established inventory of the product families in distribution centre $\mathrm{G}$ and the established sales in distribution centre $\mathrm{G}$. The reason why we opted to analyse sales area $\mathrm{G}$ was because it had the highest demand and was the most important for the company. The analysis showed that the limits which go beyond uncertainty, i.e., those that mark $100 \%$, show the maximum values of each analysed variable. The influence that the parameters have (capacity life cycle, desired inventory state, reorder point and time to be obtained) on the transport capacity variable for distribution centre $G$ was analysed. It also showed that the model is stable, and the minimum and maximum values of this variable for 
each degree of likelihood could also be known. Fig. 4 offers the effects of variation in the total inventory variable on distribution centre $\mathrm{G}$ with the changes made in the aforementioned input parameters. Compared to the previous figure, in this case we can see that the blue line, which represents the original simulation, is mostly on the blue line, which also indicates that the likelihood of occurrence is $95 \%$.

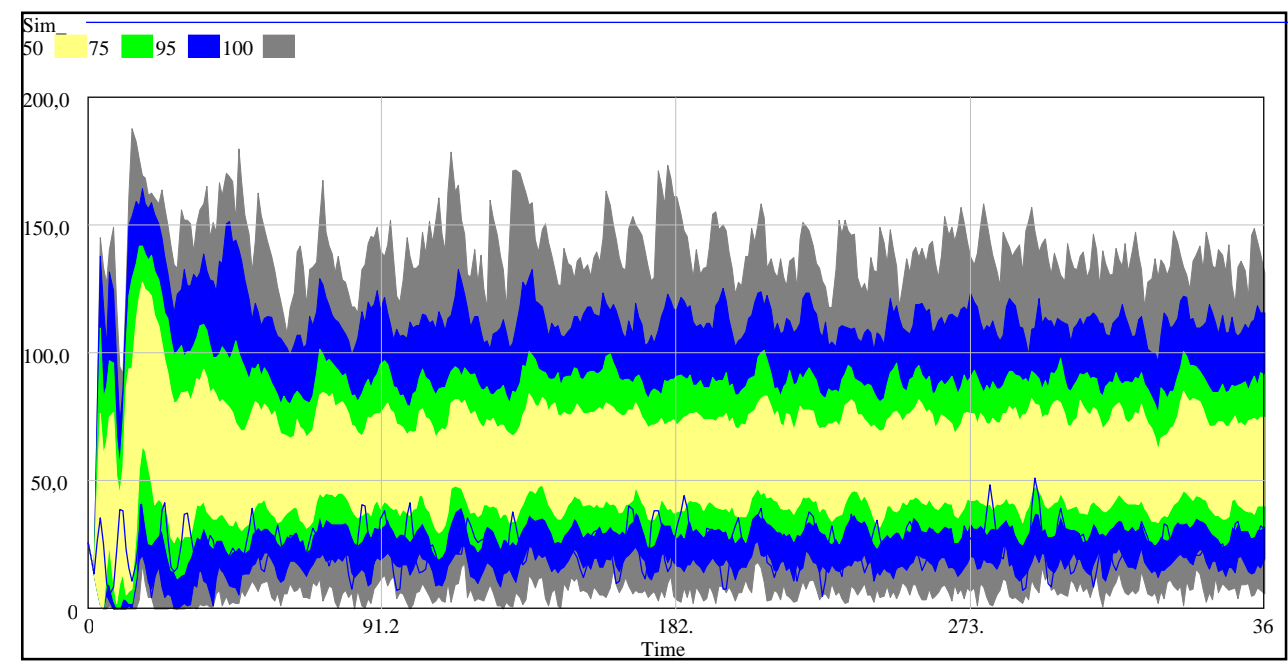

Figure 4: Sensitivity analysis of the total inventory.

\section{CONCLUSIONS}

This article considers a simulation model that represents a national distribution network of frozen food products, that could be implemented in products derived from diversified cropping systems to facilitate transport options and reduce costs. After creating the causal diagram, the flow diagram was drawn using the Vensim ${ }^{\circledR}$ simulation tool and a set of equations, input data and the relationships among the variables. Several scenarios were simulated, with which inventory management and transport capacity management were analysed. This allowed to determine the best parameters configuration to obtain the best services level in terms of fewer stockouts, as well as lower transport costs. To conclude, the best alternative was scenario 1 in which the transport capacity life cycle was 30 , the time to obtain additional transport capacity was 7 days, the reorder point was given by a 7-day stock and the amount of desired stock in the inventory was 7 days. This option was chosen because it basically gave the best results for both costs and inventory levels.

Managerial implications are oriented to introduce simulation tools in order to manage and increase performance in digital planning of supply chains. Here, the provided model could be reproduced and adapted in other food supply chains where different distribution centres exist and inventory policies and transport capacities must be managed. Additionally, the developed model could be used as a reference simulation model in other (non-food) industries/services by modelling and incorporating their main characteristics and restrictions. In this sense, this proposal reinforces and validates the convenience of an integrated decision-making process for inventory management and transport capacity planning.

Different future research lines were identified to optimise the parameters employed for the supply policy, the reorder point and the desired inventory quantity. Likewise, it is possible to restrict the storage capacity of the distribution centres, which could be a limiting factor to place replenishment orders. Although the present work observing that the inventory quantity never exceeded the storage capacity limits, the real required storage capacity that would maintain both logistic costs and service levels could be evaluated. Finally, it would be possible to work with other demand patterns, for instance, by giving a progressive percent-based sales effect per week. 
Freile, Mula, Campuzano-Bolarin: Integrating Inventory and Transport Capacity Planning ...

\section{ACKNOWLEDGEMENT}

This work was supported by the European Commission Horizon 2020 project entitled 'Crop diversification and low-input farming cross Europe: from practitioners' engagement and ecosystems services to increased revenues and value chain organisation' (Diverfarming), grant agreement 728003.

\section{REFERENCES}

[1] Tako, A. A.; Robinson, S. (2012). The application of discrete event simulation and system dynamics in the logistics and supply chain context, Decision Support Systems, Vol. 52, No. 4, 802815, doi:10.1016/j.dss.2011.11.015

[2] Forrester, J. W. (1958). Industrial dynamics: a major breakthrough for decision makers, Harvard Business Review, Vol. 36, No. 4, 37-66

[3] Sterman, J. D. (2000). Business Dynamics: Systems Thinking and Modelling for a Complex World, Irwin/McGraw-Hill, Boston

[4] Campuzano, F.; Mula, J. (2011). Supply Chain Simulation: A System Dynamics Approach for Improving Performance, Springer-Verlag, London, doi:10.1007/978-0-85729-719-8

[5] Diez, M.; Mula, J.; Campuzano-Bolarin, F. (2014). Improvement of a distribution network of a direct sale cosmetics supply chain, International Journal of Simulation Modelling, Vol. 13, No. 1, 16-29, doi:10.2507/IJSIMM13(1)2.245

[6] Moreno, R.; Mula, J.; Campuzano-Bolarin, F. (2015). Increasing the equity of a flower supply chain by improving order management and supplier selection, International Journal of Simulation Modelling, Vol. 14, No. 2, 201-214, doi:10.2507/IJSIMM14(2)2.284

[7] Horvat, D.; Wydra, S.; Lerch, C. M. (2018). Modelling and simulating the dynamics of the European demand for bio-based plastics, International Journal of Simulation Modelling, Vol. 17, No. 3, 419-430, doi:10.2507/IJSIMM17(3)435

[8] Moon, S.; Ji, W.; Moon, H.; Kim, D. (2018). A simulation of order resonance phenomenon in a supply chain triggered by reinforcing loop, International Journal of Simulation Modelling, Vol. 17, No. 2, 231-244, doi:10.2507/IJSIMM17(2)421

[9] Suryani, E.; Hendrawan, R. A.; Adipraja, P. F. E.; Indraswari, R. (2020). System dynamics simulation model for urban transportation planning: a case study, International Journal of Simulation Modelling, Vol. 19, No. 1, 5-16, doi:10.2507/IJSIMM19-1-493

[10] Georgiadis, P.; Vlachos, D.; Iakovou, E. (2005). A system dynamics modeling framework for the strategic supply chain management of food chains, Journal of Food Engineering, Vol. 70, No. 3, 351-364, doi:10.1016/j.jfoodeng.2004.06.030

[11] Sterman, J. D. (1989). Modeling managerial behavior: misperceptions of feedback in a dynamic decision making experiment, Management Science, Vol. 35, No. 3, 321-339, doi:10.1287/ mnsc.35.3.321

[12] Campuzano-Bolarín, F.; Mula, J.; Peidro, D. (2013). An extension to fuzzy estimations and system dynamics for improving supply chains, International Journal of Production Research, Vol. 51, No. 10, 3156-3166, doi:10.1080/00207543.2012.760854

[13] Pourjavad, E.; Mayorga, R. V. (2018). Optimization of a sustainable closed loop supply chain network design under uncertainty using multi-objective evolutionary algorithms, Advances in Production Engineering \& Management, Vol. 13, No. 2, 216-228, doi:10.14743/apem2018.2.286

[14] Minegishi, S.; Thiel, D. (2000). System dynamics modeling and simulation of a particular food supply chain, Simulation Practice and Theory, Vol. 8, No. 5, 321-339, doi:10.1016/S09284869(00)00026-4

[15] Fang, X.; Wang, R.; Yuan, F. J.; Gong, Y.; Cai, J. R.; Wang, Y. L. (2020). Modelling and simulation of fresh-product supply chain considering random circulation losses, International Journal of Simulation Modelling, Vol. 19, No. 1, 169-177, doi:10.2507/IJSIMM19-1-CO5

[16] Campuzano-Bolarín, F.; Mula, J.; Díaz-Madroñero, M. (2015). A supply chain dynamics model for managing perishable products under different e-business scenarios, Proceedings of the 2015 International Conference on Industrial Engineering and Systems Management, 329-337, doi:10.1109/IESM.2015.7380179 
[17] Disney, S. M.; Towill, D. R. (2003). On the bullwhip and inventory variance produced by an ordering policy, Omega, Vol. 31, No. 3, 157-167, doi:10.1016/S0305-0483(03)00028-8

[18] Abbas, K. A.; Bell, M. G. H. (1994). System dynamics applicability to transportation modelling, Transportation Research Part A: Policy and Practice, Vol. 28, No. 5, 373-390, doi:10.1016/09658564(94)90022-1

[19] Disney, S. M.; Potter, A. T.; Gardner, B. M. (2003). The impact of vendor managed inventory on transport operations, Transportation Research Part E: Logistics and Transportation Review, Vol. 39, No. 5, 363-380, doi:10.1016/S1366-5545(03)00014-0

[20] Wilson, M. C. (2007). The impact of transportation disruptions on supply chain performance, Transportation Research Part E: Logistics and Transportation Review, Vol. 43, No. 4, 295-320, doi:10.1016/j.tre.2005.09.008

[21] Mula, J.; Peidro, D.; Díaz-Madroñero, M.; Vicens, E. (2010). Mathematical programming models for supply chain production and transport planning, European Journal of Operational Research, Vol. 204, No. 3, 377-390, doi:10.1016/j.ejor.2009.09.008

[22] Mula, J.; Campuzano-Bolarin, F.; Diaz-Madroñero, F.; Carpio, K. M. (2013). A system dynamics model for the supply chain procurement transport problem: comparing spreadsheets, fuzzy programming and simulation approaches, International Journal of Production Research, Vol. 51, No. 13, 4087-4104, doi:10.1080/00207543.2013.774487

[23] Sheperd, S. P. (2014). A review of system dynamics models applied in transportation, Transportmetrica B: Transport Dynamics, Vol. 2, No. 2, 83-105, doi:10.1080/ 21680566.2014 .916236

[24] Castro, J. A. O.; Casilimas, G. W. A.; Herrera, R. M. M. (2015). Impact analysis of transport capacity and food safety in Bogota, Proceedings of the 2015 Workshop on Engineering Applications - International Congress on Engineering, 7 pages, doi:10.1109/WEA.2015.7370138

[25] Mason, R.; Chandra, L. (2006). Transport integration tools for supply chain management, International Journal of Logistics: Research and Applications, Vol. 9, No. 1, 57-74, doi:10.1080/13675560500534599

[26] Potter, A.; Lalwani, C. (2008). Investigating the impact of demand amplification on freight transport, Transport Research Part E: Logistics and Transportation Review, Vol. 44, No. 5, 835846, doi:10.1016/j.tre.2007.06.001

[27] Steinke, W. F.; Stonebraker, P. W.; Ross, D. F. (2003). Controlling bullwhips, The Journal of Commerce, Traffic World, Inc. (https://www.joc.com/controlling-bullwhips_20031012.html)

[28] Angerhofer, B. J.; Angelides, M. C. (2000). System dynamics modelling in supply chain management: research review, Proceedings of the 2000 Winter Simulation Conference, 342-351, doi:10.1109/WSC.2000.899737

[29] Guerrin, F. (2004). Simulation of stock control policies in a two-stage production system application to pig slurry management involving multiple farms, Computers and Electronics in Agriculture, Vol. 45, No. 1-3, 27-50, doi:10.1016/j.compag.2004.06.001

[30] Juntunen, J.; Juga, J. (2009). Controlling the bullwhip with transport capacity constraints, International Journal of Services and Standards, Vol. 5, No. 2, 160-171, doi:10.1504/ IJSS.2009.027221

[31] Che, X. Y. (2013). Research on inventory and transport in VMI mode, Applied Mechanics and Materials, Vol. 416, 1964-1968, doi:10.4028/www.scientific.net/amm.416-417.1964

[32] Naim, M. M.; Potter, A. T.; Mason, R. J.; Bateman, N. (2006). The role of transport flexibility in logistics provision, The International Journal of Logistics Management, Vol. 17, No. 3, 297-311, doi: $\underline{10.1108 / 09574090610717491}$

[33] Spiegler, V. L. M.; Naim, M. M. (2014). The impact of freight transport capacity limitations on supply chain dynamics, International Journal of Logistics Research and Applications, Vol. 17, No. 1, 64-88, doi: $10.1080 / 13675567.2013 .838012$

[34] Holweg, M.; Bicheno, J. (2016). The reverse amplification effect in supply chains, Pawar, K. S.; Rogers, H.; Potter, A.; Naim, M. (Eds.), Developments in Logistics and Supply Chain Management, Palgrave Macmillan, London, 52-60, doi:10.1057/9781137541253_5

[35] Villegas, F. A.; Smith, N. R. (2006). Supply chain dynamics: analysis of inventory vs. order oscillations trade-off, International Journal of Production Research, Vol. 44, No. 6, 1037-1054, doi: $10.1080 / 00207540500338203$ 